\title{
Vegetation structure of planted versus natural Aleppo pine stands along a climatic gradient in Spain
}

\author{
Enrique Hernandez-Tecles ${ }^{1} \cdot$ Yagil Osem ${ }^{2} \cdot$ Raquel Alfaro-Sanchez ${ }^{1} \cdot$ \\ Jorge de las Heras ${ }^{1}$
}

Received: 15 September 2014 / Accepted: 25 May 2015 / Published online: 17 June 2015

(C) INRA and Springer-Verlag France 2015

\begin{abstract}
- Key message Reforestation programmes have been widely used in many forest areas worldwide but scarcely compared to nearby natural woodlands. As an example, we selected a Pinus species devoted to the Mediterranean basin in order to validate the naturalness of the plantations. We found that natural Aleppo pine stands are more structurally complex with more developed and diverse understory compared to planted stands.
\end{abstract}

Handling Editor: Andreas Bolte

Contribution of the co-authors Enrique Hernandez-Tecles: proposed the study, carried out the field work, analysed data and drafted the paper. Yagil Osem: helped with experimental design, guided analysis of data, contributed writing the paper and supervised the work.

Raquel Alfaro-Sanchez: carried the field work and helped with analysis and draft paper.

Jorge de las Heras: set up and coordinated the research project, designed the experiment and supervised the work.

Electronic supplementary material The online version of this article (doi:10.1007/s13595-015-0490-9) contains supplementary material, which is available to authorized users.

Enrique Hernandez-Tecles

enrique.hernandez.tecles@gmail.com

Yagil Osem

yagil@volcani.agri.gov.il

Raquel Alfaro-Sanchez

r.alfarosanchez@gmail.com

Jorge de las Heras

jorge.heras@uclm.es

1 Department of Plant Production and Agricultural Technology,

ETSIA, University of Castilla-La Mancha, Campus Universitario s/n, 02071 Albacete, Spain

2 Department of Natural Resources, Agricultural Research Organization, Volcani Center, P.O. Box 6, 50250 Bet-Dagan, Israel
- Context Maintaining a large biodiversity is a major concern for reforestation programmes in the Mediterranean basin, which displays a large area of planted forests.

- Aims We compared mature planted forests (over 50 years old) to nearby natural forests in relation to the structure, composition and diversity of the understory vegetation. An efficient comparison method should provide guidelines to improve the effectiveness of reforestation management programmes.

- Methods We selected three pairs of nearby planted and natural Pinus halepensis Mill. stands in southeastern Spain along a precipitation gradient and compared stand overstory structure (density, basal area and canopy cover), and understory vegetation (plant cover, species richness and evenness index). - Results Pine tree density was lower but basal area was higher in natural stands than in the nearby planted stands. Natural stands displayed also higher understory plant cover and species richness, but no difference was found regarding evenness. These differences were larger in the most mesic sites and were due to the density and arrangement of the pine tree cover.

- Conclusion These results provide (i) valuable information for evaluating the success of reforestation programmes to recreate natural forest ecosystems and (ii) guidelines for silviculture and management.

Keywords Aleppo pine - Natural stands · Plantations · Mediterranean basin $\cdot$ Species composition · Ordination analysis

\section{Introduction}

The areas of primary forest and other naturally regenerated forests are decreasing and becoming increasingly fragmented, while planted forests are increasing (e.g. between 2000 and 
2010, the global area of planted forests increased by about 5 million ha per year, accounting nowadays for $7 \%$ of total forest area worldwide; FAO 2010). Apart from this, in western countries of the Mediterranean basin, the reforestation of abandoned marginal agricultural land is a major concern. Given the current trend, a further rise can be anticipated in the area of planted forests towards 300 million ha by 2020 . Throughout the twentieth century, planted forests were managed generally for timber and fibre production, but other purposes were also considered, e.g. soil erosion conservation and recreation specially in dry areas (FAO 2010; Evans 2009). Nowadays, management goals are becoming more ambitious as new aspects, such as biodiversity (Paquette and Messier 2010) and carbon sequestration (Canadell and Raupach 2008), are being considered to contribute towards multipurpose tree plantations.

Although forest plantations are complementary to natural forest woodlands and not an alternative, their management is of prime importance in order to appear less and less artificial and to take on features of naturalness (mainly when composed by native species). Objective tools to evaluate the status of plantations as well as management strategies and guidelines are needed by policy makers and forest managers, so that planted forests would become more like natural forests in terms of biodiversity and ecosystem functioning (Evans 2009). This is of prime importance in areas where extensive plantations were implemented during the last century.

The Mediterranean basin, specifically the Iberian Peninsula, contains large areas of planted forests with high proportion of native species (mainly pines) which have been widely used in order to recover the forest surface area lost over thousands of years of human timber exploitation and conversion to agricultural lands (Pausas and Austin 2001; FAO 2010). For example, in Spain, a vast reforestation and afforestation programme from 1940 to 1995 involved around 4.2 million ha of planted forests (Montero 1997) mainly for protective purposes (soil erosion mitigation, basin conservation and increase of forest surface area). Approximately $80 \%$ of the plantations corresponded to native Pinus species, which were chosen mainly for their fast-growing pioneer performance to provide rapid ground coverage, mitigate soil loss and to eventually facilitate the establishment of late successional hardwoods (Chirino et al. 2006; Zavala and Zea 2004). Aleppo pine (Pinus halepensis) was the dominant tree species used in the Iberian Peninsula dry regions (Montero 1997). In these areas, Aleppo pine can be considered as a pioneer species, usually on north-facing aspects where ecological conditions allow the following establishment of evergreen sclerophyll oaks, or as a climax species, commonly on south-facing aspects with more xeric conditions and higher fire recurrences (Gil et al. 1996; Maestre and Cortina 2004). Nowadays, most of the pine plantations in southeastern Spain are no longer exploited and have become abandoned pine woodlands, in terms of forest management. Apart from this, according to the Spanish Forest Inventory from 1986-1996 (the second inventory interval) to 1997-2007 (the third interval), Aleppo pine forest area has largely increased in southeastern Spain (e.g. $80 \%$ in the provinces of Murcia and Albacete).

Monitoring and assessing plantation actions are a costly process (Holl and Howarth 2000), and priorities may have changed since the beginning of this enterprise (Maestre and Cortina 2004). Such assessment should be based on updated long-term objectives. For example, lack of post-planting operations - due to high treatment costs, scarce public funding and low timber values - has often resulted in overly dense stands with arrested regeneration and succession (Madrigal 1998; Montero 1997). New guidelines for sustainable forest management suggest that planted forests should be managed to increase their naturalness (Montagnini 2005). Therefore, it is useful to examine mature Aleppo pine plantations and to assess their structure and function with respect to coetaneous natural Aleppo pine woodlands.

The vast majority of vegetation diversity studies in Spain have been conducted through large-scale national forest inventories (Ruiz-Benito et al. 2012; Martin-Queller et al. 2011), which provide a very important source of information on this scale. Other regional studies (Chirino et al. 2006; Bellot et al. 2004; Maestre et al. 2003) conducted in dry Mediterranean and semiarid regions in Spain have focused mainly on comparing Aleppo pine plantations with natural shrublands or grasslands, but not on comparing mature plantations with natural Aleppo pine woodlands. Studies that compare planted versus natural Aleppo pine stands, including overstory and understory vegetation structure and composition, could prove extremely useful for future management guidelines. To the best of our knowledge, no such attempt has been made in southeastern Spain or in any other nearby Mediterranean region.

Our general research aim was to compare vegetation diversity, composition and structure in natural versus planted Aleppo pine forests, and to identify possible environmental and silvicultural causes for variation. We compared stand understory vegetation structure and floristic composition in mature planted versus natural Aleppo pine woodlands considering a geo-climatic range.

\section{Material and methods}

\subsection{Study area and sites}

Three study sites were chosen in southeastern Spain, close to the villages of (1) Yeste, (2) Liétor and (3) Calasparra (in the provinces of Albacete and Murcia). The chosen sites are representative of the Mesomediterranean bioclimatic belt (RivasMartínez et al. 1987) and cover all the subdivisions: Low for 
Calasparra (Arid, hereafter), Medium for Liétor (Medium, hereafter) and High for Yeste (Humid, hereafter) (Table 1). Climatic variables were extracted from a $1-\mathrm{km}^{2}$ spatial resolution map (Gonzalo 2008), showing that altitude and mean annual precipitation (precipitation, hereafter) are closely correlated.

Potential natural vegetation (Blanco et al. 1997) varied from a mixed pine-oak forest of $P$. halepensis, Pinus pinaster Ait. and Quercus ilex subsp. ballota (Desf.) Samp. at the Humid site to Aleppo pine woodland with kermes oak (Quercus coccifera L.) at the Medium and Arid sites. In these study areas, with adverse environmental conditions (e.g. poor soils, severe droughts and fire recurrence), the potential natural vegetation appeared in small microsites of north-facing slopes. Topographic aspect (south-facing), slope (under 5$10 \%$ ), soil (Xerocrep inceptisol; CSIC 1968) and bedrock type (limestone; IGME 1975) were homogeneous among selected stands at the three sites.

For each site, two forest types were selected (one natural stand of Aleppo pine and one planted of the same species). The natural stands are representative of the largest continuous area of Aleppo pine natural distribution corresponding to the Western Mediterranean basin (Fady et al. 2003). Planted stands were characterised by evenly spaced rows of trees and a consistent mechanical site preparation protocol.

\subsection{Experimental design and sampling}

Three square plots of $400 \mathrm{~m}^{2}$ were randomly set in each planted and natural forest in each site with a total of 18 plots distributed among the three sites and two forest types. The distance between natural and planted stands per site was less than $1 \mathrm{~km}$.

The stand overstory in both planted and natural stands was monospecific composed of mature Aleppo pines. Average tree age was similar among the two forest types - approximately 50 and 55 years old in planted and natural stands, respectively-as measured through tree ring coring. However, the age distribution was different, as planted stands are even-aged whereas natural stands are multi-aged (including trees of up to $\sim 70$ years old).

The variables measured in each of the research plots were as follows: density of mature pine trees, $\mathrm{DBH}$ and mean crown diameter measured along two perpendicular directions. For each stand, the following parameters were calculated: pine tree density (number of trees ha ${ }^{-1}$ ), pine stem basal area $\left(\mathrm{m}^{2} \mathrm{ha}^{-1}\right)$ and canopy cover $(\%)$ (Table 2$)$. For the calculation of stand canopy cover, the overlapping between tree crowns was considered and deducted.

Understory species cover was measured using the lineintercept method (Boyd et al. 2007) with six equidistant linear transects of $15 \mathrm{~m}$ measured in spring and autumn 2011 in each plot. All the understory plants intercepting each transect were recorded. Overlapping between plant cover was not discarded; therefore, final total cover values could be above $100 \%$. For each plot, total vegetation cover and two diversity indices were calculated, e.g. species richness and evenness (Pielou 1966). In order to obtain life form spectra, plant species were classified according to life form categories (Castroviejo 19862012; Tutin et al. 1986-1993), where each species was assigned to its higher potential life form. The percent cover of understory woody vegetation and herbs was distinguished, with the former including trees, shrubs and dwarf shrubs, and the latter including perennial and annual herbs.

\subsection{Statistical analysis}

Multifactorial analyses of variance (two-way ANOVA) were used to evaluate the effects of the forest type (planted, natural) and precipitation level (Humid, Medium, Arid) on stand characteristics, understory vegetation cover, species richness and evenness index. Each response variable was examined for the normal distribution of errors using the Shapiro-Wilk statistic, and for homogeneity of variance using the Levene's and

Table 1 Climatic and environmental variables of the study sites

\begin{tabular}{|c|c|c|c|}
\hline Site name & Yeste & Liétor & Calasparra \\
\hline Coordinates & $\begin{array}{l}38^{\circ} 20^{\prime} \mathrm{N} \text { to } \\
2^{\circ} 20^{\prime} \mathrm{W}\end{array}$ & $\begin{array}{l}38^{\circ} 32^{\prime} \mathrm{N} \text { to } \\
1^{\circ} 57^{\prime} \mathrm{W}\end{array}$ & $\begin{array}{l}38^{\circ} 16^{\prime} \mathrm{N} \text { to } \\
1^{\circ} 38^{\prime} \mathrm{W}\end{array}$ \\
\hline Mean annual precipitation $(\mathrm{mm} \pm \mathrm{SE})^{\mathrm{a}}$ & $595 \pm 15$ & $417 \pm 19$ & $332 \pm 13$ \\
\hline Mean maximum temperature of the warmest month $\left({ }^{\circ} \mathrm{C}\right)^{\mathrm{a}}$ & 30.9 & 32.9 & 34.6 \\
\hline Mean minimum temperature of the coldest month $\left({ }^{\circ} \mathrm{C}\right)^{\mathrm{a}}$ & 2.2 & 1.8 & 2.0 \\
\hline Phytoclimate $^{\mathrm{a}}$ & VI(IV)1 & IV3 & IV1 \\
\hline Bioclimate $^{\mathrm{b}}$ & $\begin{array}{l}\text { High } \\
\text { Mesomediterranean }\end{array}$ & $\begin{array}{l}\text { Medium } \\
\text { Mesomediterranean }\end{array}$ & $\begin{array}{l}\text { Low } \\
\text { Mesomediterranean }\end{array}$ \\
\hline Nomenclature & Humid & Medium & Arid \\
\hline
\end{tabular}

a (Gonzalo 2008)

${ }^{\mathrm{b}}$ (Rivas-Martínez et al. 1987) 
Table 2 Mean $( \pm \mathrm{SE})$ stand density, basal area and canopy cover of Aleppo pine forest type (natural versus planted) within precipitation (Humid, Medium and Arid)

\begin{tabular}{lllcc}
\hline & Forest type & $\begin{array}{l}\text { Density } \\
(\text { trees ha }\end{array}$ & $\begin{array}{l}\text { Basal area } \\
\left(\mathrm{m}^{2} \mathrm{ha}^{-1}\right)\end{array}$ & $\begin{array}{l}\text { Canopy cover } \\
(\%)\end{array}$ \\
\hline Humid & Natural & $340 \pm 50$ & $18.1 \pm 1.4$ & $75 \pm 6$ \\
& Planted & $590 \pm 30$ & $15.8 \pm 0.4$ & $76.8 \pm 2.1$ \\
\multirow{4}{*}{ Medium } & Natural & $380 \pm 40$ & $9.4 \pm 1.1$ & $60 \pm 3$ \\
& Planted & $730 \pm 30$ & $7.2 \pm 0.6$ & $66 \pm 3$ \\
\multirow{4}{*}{ Arid } & Natural & $390 \pm 30$ & $8.8 \pm 0.8$ & $55 \pm 4$ \\
& Planted & $780 \pm 40$ & $3.9 \pm 0.4$ & $36.5 \pm 2.1$ \\
\hline
\end{tabular}

The number of plots per forest is 3

Bartlett's test. If the assumptions of ANOVA were not met, not even after common mathematical transformations, then ANOVAs using rank-transformed data were conducted, as outlined in Conover and Iman (1981). The Tukey-Kramer HSD test was used for post hoc comparisons.

Ordination analyses were applied to examine the variation in the species composition among forest stands. The species cover data were $\log$-transformed $(\log x+1)$ to minimise the skewness of abundant species, and linear models were chosen according to the protocol described by ter Braak and Smilauer (2012). First, a principal component analysis (PCA) was carried out to observe the unconstrained ordination of species composition in the various forest plots. Second, we did a redundancy analysis (RDA) to investigate the relationship between forest type and precipitation on the one hand, and species composition on the other. The significance of these effects was determined by means of the Monte Carlo permutation tests.

The statistical packages used were $J M P 9$ (SAS Institute, Cary, NC, US) and Canoco v5 (ter Braak and Smilauer 2012).

\section{Results}

\subsection{Overstory stand characteristics}

Natural forests showed lower pine tree density than planted ones (mean values of 372 and 710 trees $^{-1} \mathrm{a}^{-1}$ for natural and planted, respectively, Table 2), and the effect of forest type was significant (Table 3). Stem basal area, however, was significantly higher in natural stands $\left(\sim 12\right.$ vs. $8 \mathrm{~m}^{2} \mathrm{ha}^{-1}$ for natural and planted, respectively) and was correlated to precipitation within both forest types (Tables 2 and 3). Density, as well as pine stem basal area, presented no significant forest type $\times$ precipitation interaction (Table 3 ). No forest type effect was found for pine canopy cover. Instead, we found a significant forest type $\times$ precipitation interaction (Table 2) indicating that the canopy cover values were very close in the planted and natural stands at the Humid and Medium sites, while at the Arid site natural stands presented higher cover values than planted ones (Table 3 and Fig. 2).

\subsection{Understory vegetation cover and diversity}

Total and woody understory vegetation cover were significantly higher in natural stands than in planted ones in all three study sites (approximately 1.5- to 15 -fold; Fig. 1) exhibiting a significant forest type $\times$ precipitation interaction (Table 4 ). The biggest difference between natural and planted stands was found for understory woody vegetation cover at the Humid site (approximately 105 to $7 \%$, respectively; Fig. 1), while the smallest difference was observed for the total cover values at the Arid site (approximately 130 to $95 \%$, respectively; Fig. 1). Total vegetation cover increased with decreasing precipitation, while no such relationship was found for UWV cover.

The total number of understory species recorded across the entire experimental setup was 78 , where woody species were represented by 34 species. Total and woody species richness was significantly higher in natural stands than in planted ones. The evenness values showed no significant differences for total nor for woody vegetation of the studied sites regarding forest type, precipitation and their interaction (Table 4 and Fig. 1).

\subsection{Life forms}

Understory woody vegetation life forms (e.g. trees, shrubs and dwarf shrubs) and perennial herbs cover as well as species richness values (Supplementary Table S1) exhibited a significant forest type $\times$ precipitation interaction. On the other hand, the interaction was never significant regarding evenness values for all the different life forms (Supplementary Table S1).

The trees, shrubs and dwarf shrub cover and richness values were significantly higher in natural than in planted stands (Supplementary Table S2), and they increased significantly across the precipitation gradient (except for shrubs cover).

The perennial herbs cover values were significantly higher (approximately twofold) in natural stands than in planted ones, while no forest type effect was detected for the richness of perennial herbs.

Regarding annual herbs, a significant forest type $\times$ precipitation interaction was observed for species richness which obtained higher values in planted stands than in natural stands (Supplementary Tables S1 and S2), with more pronounced differences noted at the Medium site. 
Table 3 Two-way ANOVA of the effect of forest type (natural versus planted), precipitation (Humid, Medium and Arid) and their interaction term on overstory stand parameters

\begin{tabular}{|c|c|c|c|c|c|c|}
\hline Stand parameter & $R^{2}$ & Variable & SS & df & $\mathrm{F}$ & $P$ \\
\hline \multirow[t]{3}{*}{ Density } & \multirow[t]{3}{*}{81.6} & Forest type & 715327.0 & 1 & 101.9 & $* * * *$ \\
\hline & & Precipitation & 48374.0 & 2 & 3.4 & n.s. \\
\hline & & Forest type $\times$ precipitation & 17442.0 & 2 & 1.2 & n.s. \\
\hline \multirow[t]{3}{*}{ Basal area } & \multirow[t]{3}{*}{85.7} & Forest type & 83.1 & 1 & 22.0 & $* * * *$ \\
\hline & & Precipitation & 468.0 & 2 & 62.0 & $* * * *$ \\
\hline & & Forest type $\times$ precipitation & 71.7 & 2 & 1.2 & n.s. \\
\hline \multirow[t]{3}{*}{ Canopy cover } & \multirow[t]{3}{*}{73.4} & Forest type & 117.3 & 1 & 2.0 & n.s. \\
\hline & & Precipitation & 3351.2 & 2 & 28.8 & $* * * *$ \\
\hline & & Forest type $\times$ precipitation & 663.5 & 2 & 5.7 & * \\
\hline
\end{tabular}

n.s. not significant

$* P<0.05 ; * * * * P<0.0001$

\subsection{Species composition}

Understory woody species composition showed better discrimination among stands than the entire understory species composition. Therefore, perennial and annual herbs were removed from the ordination analyses. In the unconstrained linear ordination method (PCA), the first two axes explained $62.10 \%$ of the variation in the woody species composition between the studied forest stands. Natural stands were clearly separated from planted ones on the ordination matrix. Separation among sites on the ordination matrix was also evident within both forest types. However, this separation was much more pronounced in natural stands than in planted ones indicating that planted stands were more homogeneous than natural ones (Fig. 2).

In a constrained ordination analysis (RDA) of understory woody vegetation composition, and by considering forest type and precipitation as the main factors, the two factors significantly accounted for nearly $80 \%$ of the variation explained by the first two axes in the unconstrained analysis (Fig. 3). Two tree species, P. halepensis seedlings and Juniperus oxycedrus L., and two shrubs species, Cistus clusii Dunal in DC. and Rosmarinus officinalis L., showed the closest association with natural stands. Among the natural stands, several tree and shrub species, e.g. Cistus albidus L., Q. ilex subsp. ballota and $Q$. coccifera, were
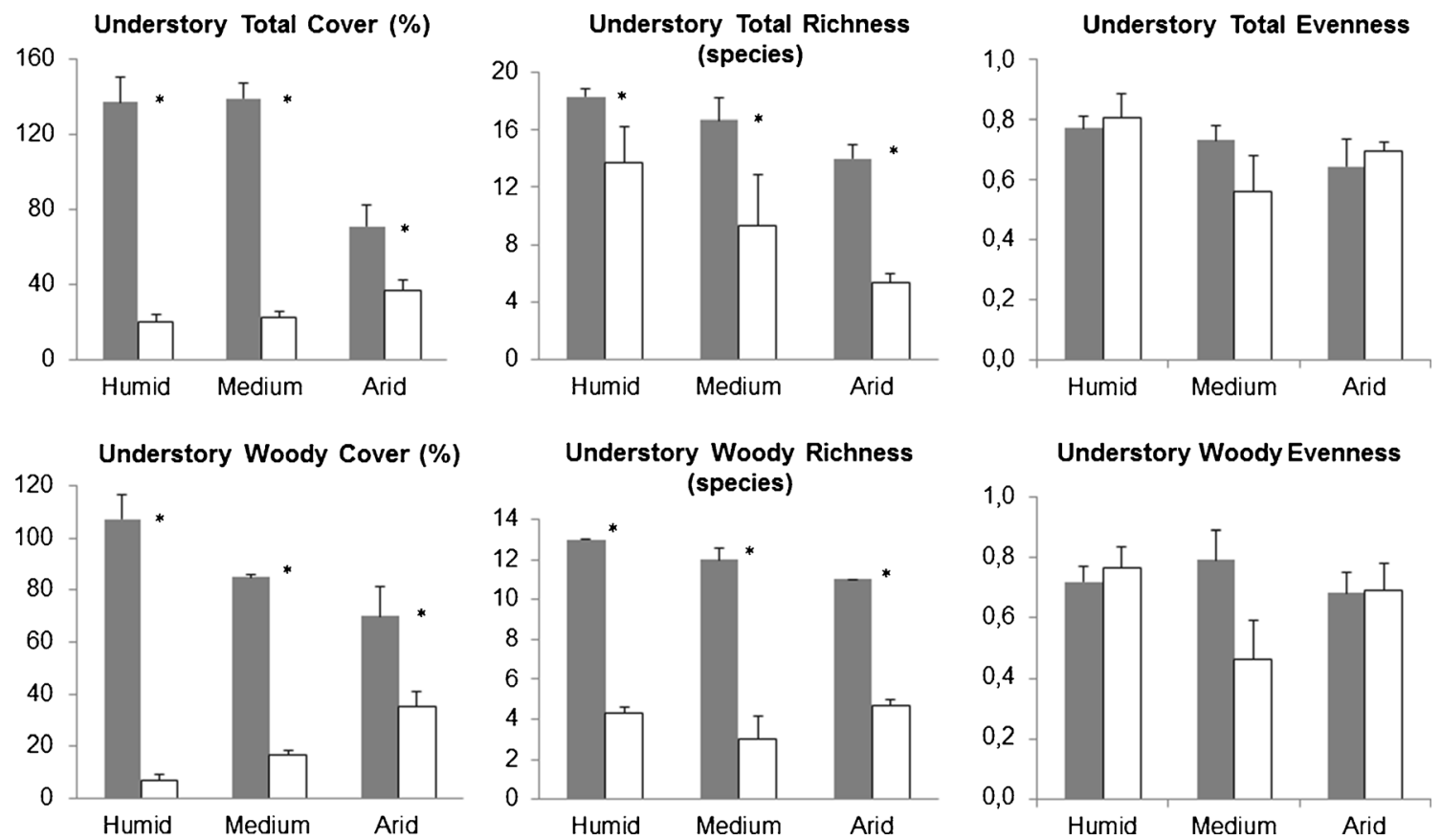

Fig. 1 Mean $( \pm$ SE) for total and woody understory vegetation cover, richness and evenness in natural (grey) and planted (open) stands of $P$. halepensis forests in Humid (595 mm year ${ }^{-1}$ ), Medium $\left(417 \mathrm{~mm} \mathrm{year}^{-1}\right.$ ) and Arid sites (332 $\mathrm{mm} \mathrm{year}^{-1}$ ) in southeastern Spain 
Table 4 Two-way ANOVA of the effect of forest type (natural versus planted), precipitation (Humid, Medium and Arid) and their interaction on vegetation cover (total and woody understory (UWV)) and diversity (richness and evenness) parameters

\begin{tabular}{|c|c|c|c|c|c|c|}
\hline & $R^{2}$ & Variable & SS & df & $\mathrm{F}$ & $P$ \\
\hline \multirow[t]{3}{*}{ Total cover } & \multirow[t]{3}{*}{95.6} & Forest type & 42815.0 & 1 & 288.7 & $* * * *$ \\
\hline & & Precipitation & 3717.0 & 2 & 12.5 & $*$ \\
\hline & & Forest type $\times$ precipitation & 8363.0 & 2 & 28.2 & $* * * *$ \\
\hline \multirow[t]{3}{*}{ Total richness } & \multirow[t]{3}{*}{74.5} & Forest type & 234.7 & 1 & 38.4 & $* * * *$ \\
\hline & & Precipitation & 85.4 & 2 & 7.0 & $*$ \\
\hline & & Forest type $\times$ precipitation & 14.8 & 2 & 1.2 & n.s. \\
\hline \multirow[t]{3}{*}{ Total evenness } & \multirow[t]{3}{*}{42.5} & Forest type & 0.5 & 1 & 0.4 & n.s. \\
\hline & & Precipitation & 7.8 & 2 & 2.5 & n.s. \\
\hline & & Forest type $\times$ precipitation & 5.7 & 2 & 1.8 & n.s. \\
\hline \multirow[t]{3}{*}{ UWV cover } & \multirow[t]{3}{*}{92.1} & Forest type & 21636.2 & 1 & 178.9 & $* * * *$ \\
\hline & & Precipitation & 157.0 & 2 & 0.6 & n.s. \\
\hline & & Forest type $\times$ precipitation & 2820.3 & 2 & 11.7 & $*$ \\
\hline \multirow[t]{3}{*}{ UWV richness } & \multirow[t]{3}{*}{94.8} & Forest type & 288.0 & 1 & 304.9 & $* * * *$ \\
\hline & & Precipitation & 4.3 & 2 & 2.3 & n.s. \\
\hline & & Forest type $\times$ precipitation & 6.3 & 2 & 3.4 & n.s. \\
\hline \multirow[t]{3}{*}{ UWV evenness } & \multirow[t]{3}{*}{56.7} & Forest type & 6.7 & 1 & 2.8 & n.s. \\
\hline & & Precipitation & 9.3 & 2 & 1.9 & n.s. \\
\hline & & Forest type $\times$ precipitation & 21.8 & 2 & 3.6 & n.s. \\
\hline
\end{tabular}

n.s. not significant

$* P<0.05 ; * * * * P<0.0001$ clearly associated with the higher precipitation level (Humid site), while other species, e.g. Thymus vulgaris L. (dwarf shrub, also in planted stands) and Coronilla juncea L. (shrub), associated greatly with the lower precipitation level (Arid site). In the planted stands, only one dwarf shrub speciesSedum sediforme (Jacq.) Pau-was closely associated with the Humid site.

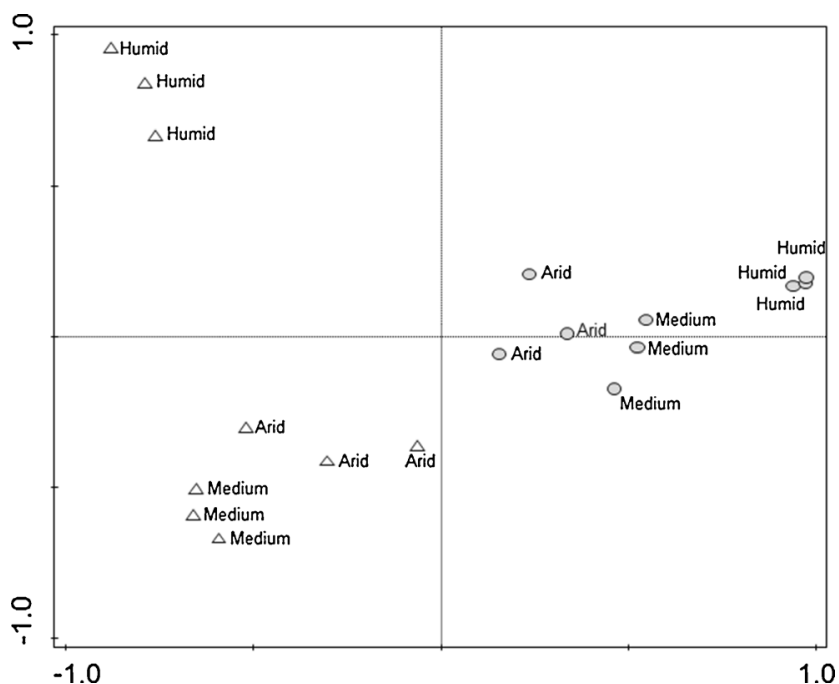

Fig. 2 PCA of woody understory vegetation composition (with log transformation) of planted and natural Aleppo pine stands in three climatic regions sampled plots (grey circles for planted and open triangles for natural stands)

\section{Discussion}

\subsection{Overstory stand characteristics}

Aleppo pine stand characteristics related strongly to forest type (natural or planted) and to the site climatic differentiation represented through the precipitation gradient. In general,

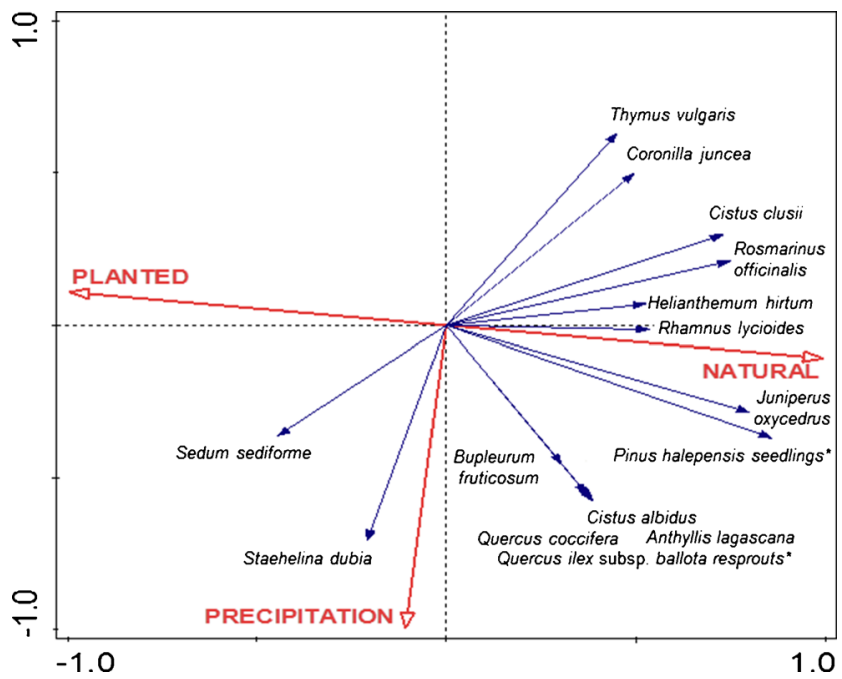

Fig. 3 RDA of understory woody vegetation (with $\log$ transformation) showing the species composition according to forest type (natural and planted) and precipitation gradient. *Seedlings or resprouts were considered when the diameter at the breast height was under $7.5 \mathrm{~cm}$ 
planted stands presented significantly higher stand densities, whereas natural stands had higher basal area values. Thus, overstory Aleppo pine trees in natural stands were significantly larger and achieved higher stand performance per unit area with fewer trees. This fact could be the result of natural stands being less dense as well as uneven aged allowing high performance of dominant trees while planted stands suffering from overcrowding and intense competition. Slightly higher average tree age in natural versus planted stands may have also accounted for some of this variation. Although not directly measured, the two origins differed strongly in terms of their tree spatial arrangement, which was much more heterogeneous in natural than in planted stands. Planted stands remained with their original lineal distribution of trees where no silvicultural treatments have been applied since trees were planted.

The average tree densities reported in this study for the mature $P$. halepensis planted stands $\left(\sim 700\right.$ trees $\left.\mathrm{ha}^{-1}\right)$ are similar to those in other studies in semiarid regions of Spain (Maestre and Cortina 2004). There may be several explanations for the fact that natural $P$. halepensis stands were significantly less dense than planted ones: the natural stands originating from natural regeneration or spontaneous colonization may have been less dense from the very beginning in comparison with plantations. Additionally, as they are multi-aged, they may have undergone more advanced self-thinning thanks to a more substantial dominance of some trees over the others. This and more, traditional silvicultural practices may have been applied to these natural stands in the past by combining timber production with rangelands for domestic grazing, which could have led to the more open and less homogenous spatial distribution of trees observed.

\subsection{Understory vegetation structure and floristic composition}

In general, a larger portion of variation in the understory vegetation structure was explained by forest type rather than by precipitation. Regarding the woody species composition of natural stands, trees and shrubs were more characteristic of the Humid site (Quercus spp. and Cistus albidus), whereas shrubs and dwarf shrubs were more representative of the Medium and Arid sites. Quercus spp. have been previously reported in the understory of natural Aleppo pine stands in similar mesic areas such as at the Humid site of the present study (Lookingbill and Zavala 2000). The absence of heavy human intervention in natural stands as compared to planted ones which have undergone intense site preparation and dense planting could explain the prevalence of later successional species (such as $J$. oxycedrus or Quercus spp.), as well as higher potential life forms (e.g. woody vegetation in general, and trees in particular) in the former than in the latter. Additionally, the development of multi-aged structure with heterogenic spatial tree distribution in natural stands, compared to the homogeneous structure of planted stands, has led to higher occurrence of overstory gaps in the natural stands favouring the establishment and development of understory vegetation. Nevertheless, other factors, such as history of land use in relation to human interference and specific habitat conditions, may have contributed to the differences observed in understory characteristics. Understanding the importance of all these factors may contribute greatly by acknowledging the status of vegetation abundance (cover) and species richness of each forest stand in order to plan management strategies that would lead to the desired structure of both natural and planted $P$. halepensis woodlands.

Total understory vegetation cover (including woody and herbaceous) was found to be negatively related to precipitation, while understory diversity was related positively to precipitation. Higher understory vegetation cover at the Arid (natural and planted stands) and Medium (natural stands only) sites have most likely resulted from a lower canopy density (Arduini and Ercoli 2012) and the presence of esparto grass (Macrochloa tenacissima (L.) Kunth), which was extensively planted mainly for fibre harvesting in these areas in the twentieth century (Cortina et al. 2009). All planted stands were homogeneous in esparto grass abundance, and the mechanical site protocol was consistent in both sites. This has resulted in increased herbaceous vegetation cover, but also in reduced woody vegetation cover and overall species diversity (Alados et al. 2006; Ramírez et al. 2006). In this case, specific management should be applied in order to control esparto grass leaving more space for the return of native woody species.

In general, there were no differences regarding evenness distribution of species between stands, especially regarding total and woody understory vegetation. This means that Shannon index would have been directly correlated with species richness, therefore not adding extra information about the understory floristic distribution (Liu 1995).

In a close semiarid area of southeastern Spain, Chirino et al. (2006) reported poorer vegetation cover and species richness in the understory of Aleppo pine plantations. These authors made a comparison with adjacent natural grasslands and shrublands, but not with nearby Aleppo pine natural stands.

A cover-richness relationship occurred in natural stands where total vegetation cover and, to a greater extent, woody cover were linearly and positively related to total and woody species richness. Such a relationship has also been reported in nearby naturally regenerated Aleppo pine stands (GonzálezOchoa et al. 2004; Moya et al. 2009). However, in the planted stands of the present study, understory vegetation cover and species richness were not related. This may have resulted from the fact that very few species were actually present in the planted stands, which led to high vegetation cover with low diversity. 
In summary, the understory vegetation in mature natural $P$. halepensis forests is well developed with high number of species and cover of variable life forms. Yet, in plantations, the understory is dominated by a homogeneous herbaceous cover and shows low species richness. In the present study, we found understory woody vegetation structure to be a sensitive diversity indicator for ecosystem status, as found in previous studies in other Mediterranean forests (Osem et al. 2012; RuizBenito et al. 2012).

\subsection{Overstory-understory relationship}

When looking at the entire research setup, a significant overstory-understory relationship emerged which revealed greater understory development (vegetation cover, number of species and later successional species), with increasing stand basal area and decreasing stem density, both of which characterized natural stands and higher precipitation. However, when observing the overstory canopy cover, a more complex overstory-understory relationship appeared in which natural stands presented a positive overstoryunderstory relationship, whereas planted stands showed a negative relationship. A negative overstory-understory relationship, as found in planted stands, is commonly attributed to light interception (shading) and to competition for belowground resources. A positive overstory-understory relationship, however, may be attributed to forest multi-age and complexity, as expected in well-developed natural forest systems. Uneven tree distribution and low density of well-developed trees are typical of the studied natural stands and should likely result in a high spatial heterogeneity in the availability of aboveground and belowground resources to understory vegetation, including completely unshaded gaps (Broncano et al. 1998). These gaps would have favoured the establishment of the different lightdemanding species present as seeds and/or seedlings (Pausas and Austin 2001), such as presented in other Pinus species plantations (Arduini and Ercoli 2012; Arduini et al. 2013). Thus, in simply structured dense forest systems with homogeneous tree size and spatial distribution, understory development should be expected to be negatively affected by increasing overstory development (cover) due to intensified competitive pressure. However, in heterogeneously structured forest systems, increased overstory development should not be necessarily associated with diminished understory as this development reflects increased system maturity and complexity.

Further investigation of stand characteristics (e.g. spatial arrangement, age structure and stem diameter distribution) in natural forest stands and their relationships with climatic variables may help in the subscription of new guidelines for the sustainable management of planted Aleppo pine forests.

\subsection{Management considerations}

By observing the main differences between natural and planted stands, management practices should focus primarily on reducing mature tree densities in pine plantations together with creating an uneven spatial tree distribution, including completely cleared gaps of variable sizes. This has also been proposed for nearby natural regenerated areas after forest fires (De las Heras et al. 2002; Moya et al. 2009). Additionally, thinning strategies should strive to create an uneven spatial tree distribution, including completely cleared gaps of variable sizes. This should result in a more natural-like forest structure and ought to contribute largely to forest diversity and complexity. The introduction of seed sources through planting towards late successional woody species (mainly trees and shrubs) should be considered as a means by which to enhance forest understory development (diversity and cover) (RuizBenito et al. 2012).

One key question to consider is the age at which $P$. halepensis plantation interventions should be applied to most efficiently direct them towards increased complexity, diversity and sustainability. Given the financial limitations for intensive care in such systems of low commercial value, this question is certainly not a trivial one. It would also be important to test management strategies leading to the conversion of evenaged plantations into multi-aged stands with higher spatial heterogeneity and complexity. Further research is required to develop such management guidelines by taking into account environmental variability.

\section{Conclusions}

Low density of large trees and higher stand performance as found in the natural stands are likely desirable for several forestry aspects such as plant diversity, carbon storage, fire hazard reduction, tree longevity and other forest aesthetic values. Based on their current structure, planted stands are not expected to achieve these goals in the near future. Intervention is likely needed in order to break the arrested succession caused by artificial planting. It is essential to promote natural-like characteristics in planted Aleppo pine stands and achieve a more diverse, complex and successionaly developed vegetation structure.

Acknowledgments We are grateful to José María Herranz for his valuable help with the plant inventories, and to Javier Hedo and Daniel Moya for their field assistance. We thank Helen Warburton for reviewing the language.

Funding The study has been co-funded by Projects P01109-0096-3367 and POII10-0112-7316, of the Regional Council of Castilla-La Mancha (Spain), and CONSOLIDER-INGENIO 2010: MONTES (CSD 200800040) of the Spanish Ministry of Science and Innovation. 


\section{References}

Alados CL, Gotor R, Ballester P, Navas D, Escos JM, Navarro T, Cabezudo B (2006) Association between competition and facilitation processes and vegetation spatial patterns in alpha steppes. Biol J Linn Soc 87:103-113. doi:10.1111/j.10958312.2006.00559.x

Arduini I, Ercoli L (2012) Recovery of understory vegetation in clear-cut stone pine (Pinus pinea L.) plantations. Plant Biosyst 146:244-258

Arduini I, Orlandi C, Mariotti M, Masoni A (2013) Seed banks and forest recruitment after disturbance: the composition and abundance of seed after the clear-cut of stone pine (Pinus pinea L.) plantations. Pol J Ecol 61:457-470

Bellot J, Maestre FT, Chirino E, Hernandez N, de Urbina JO (2004) Afforestation with Pinus halepensis reduces native shrub performance in a Mediterranean semiarid area. Acta Oecol 25:7-15. doi: 10.1016/j.actao.2003.10.001

Blanco E, Casado M, Costa M, Escribano R, García M, Génova M, Gómez A, Gómez F, Moreno J, Morla C (1997) Los bosques ibéricos: una interpretación geobotánica. Planeta, Madrid

Boyd CS, Bates JD, Miller RF (2007) The influence of gap size on sagebrush cover estimates with the use of line intercept technique. Rangel Ecol Manag 60:199-202. doi:10.2111/05-226r2.1

Broncano MJ, Riba M, Retana J (1998) Seed germination and seedling performance of two Mediterranean tree species, holm oak (Quercus ilex L.) and Aleppo pine (Pinus halepensis Mill.): a multifactor experimental approach. Plant Ecol 138:17-26. doi:10.1023/ a: 1009784215900

Canadell JG, Raupach MR (2008) Managing forests for climate change mitigation. Science 320:1456-1457. doi:10.1126/ science. 1155458

Castroviejo S (1986-2012) Flora Iberica vol 1-8, 10-15, 17-18, 21. Real Jardín Botánico, CSIC, Madrid

Chirino E, Bonet A, Bellot J, Sanchez JR (2006) Effects of 30-year-old Aleppo pine plantations on runoff, soil erosion, and plant diversity in a semi-arid landscape in south-eastem Spain. Catena 65:19-29. doi:10.1016/j.catena.2005.09.003

Conover W, Iman RL (1981) Rank transformations as a bridge between parametric and nonparametric statistics. Am Stat 35:124-129

Cortina J, Maestre FT, Ramírez D (2009) Innovations in Semiarid Land Restoration. The case of Stipa tenacissima L. steppes. In: Bautista S, Aronson R, J., Vallejo R (eds) Land Restoration to Combat Desertification. Innovative Approaches, Quality Control and Project Evaluation. Fundación CEAM, Valencia, pp 121-144

CSIC (1968) Mapa de Suelos de España (1:1.000.000). Consejo Superior Investigaciones Científicas (CSIC), Madrid

De las Heras J, Martínez-Sánchez J, González-Ochoa A, Ferrandis P, Herranz J (2002) Establishment of Pinus halepensis Mill. saplings following fire: effects of competition with shrub species. Acta Oecol 23:91-97

Evans J (2009) Planted forests: uses, impacts and sustainability. Food and Agriculture Organization of the United Nations (FAO), Rome

Fady B, Semerci H, Vendramin GG (2003) EUFORGEN technical guidelines for genetic conservation and use for Aleppo pine (Pinus halepensis) and Brutia pine (Pinus brutia). International Plant Genetic Resources Institute, Rome

FAO (2010) Global forest resources assessment 2010. Food and Agriculture Organization of the United Nations (FAO), Rome

Gil L, Díaz-Fernández P, Jiménez M, Roldán M, Alía R, Agúndez D, De Miguel J, Martín S, De Tuerto M (1996) Regiones de procedencia de Pinus halepensis Mill. OA Parques Nacionales, Madrid
Gonzalez-Ochoa AI, Lopez-Serrano FR, de las Heras J (2004) Does postfire forest management increase tree growth and cone production in Pinus halepensis? For Ecol Manag 188:235-247. doi:10.1016/j. foreco.2003.07.015

Gonzalo J (2008) Diagnosis fitoclimática de la España peninsular. Actualización y análisis geoestadístico aplicado. Universidad Politécnica de Madrid, Escuela Técnica Superior de Ingenieros de Montes, Madrid

Holl KD, Howarth RB (2000) Paying for restoration. Restor Ecol 8:260267. doi:10.1046/j.1526-100x.2000.80037.x

IGME (1975) Mapa Geológico de España a escala 1: 50.000 (MAGNA). Hojas: Liétor (842), Yeste (866) y Calasparra (890). Instituto Geológico y Minero de España (IGME), Madrid

Liu G (1995) A model for species diversity monitoring at community level and its applications. Environ Monit Assess 34:271-287. doi: 10.1007/BF00554798

Lookingbill T, Zavala M (2000) Spatial pattern of Quercus ilex and Quercus pubescens recruitment in Pinus halepensis dominated woodlands. J Veg Sci 11:607-612. doi:10.2307/ 3246590

Madrigal A (1998) Problemática de la ordenación de masas artificiales en España. Cuaderno de las Sociedad Española de Ciencias Forestales 6:13-20

Maestre FT, Cortina J (2004) Are Pinus halepensis plantations useful as a restoration tool in semiarid Mediterranean areas? For Ecol Manag 198:303-317. doi:10.1016/j.foreco.2004.05.040

Maestre FT, Cortina J, Bautista S, Bellot J (2003) Does Pinus halepensis facilitate the establishment of shrubs in Mediterranean semi-arid afforestations? For Ecol Manag 176:147-160. doi:10.1016/s03781127(02)00269-4

Martin-Queller E, Gil-Tena A, Saura S (2011) Species richness of woody plants in the landscapes of Central Spain: the role of management disturbances, environment and non-stationarity. J Veg Sci 22:238 250. doi:10.1111/j.1654-1103.2010.01242.x

Montagnini F (2005) Attempting to restore biodiversity in evenaged plantations. In: Mansourian S, Vallauri D, Dudley N (eds) Forest Restoration in Landscapes. Springer, New York, pp 384-391

Montero G (1997) Breve descripción del proceso repoblador en España (1940-1995). Legno Celulosa Carta 4:35-42

Moya D, De las Heras J, Lopez-Serrano FR, Condes S, Alberdi I (2009) Structural patterns and biodiversity in burned and managed Aleppo pine stands. Plant Ecol 200:217-228. doi: 10.1007/s11258-008-9446-6

Osem Y, Zangy E, Bney-Moshe E, Moshe Y (2012) Understory woody vegetation in manmade Mediterranean pine forests: variation in community structure along a rainfall gradient. Eur J For Res 131: 693-704. doi:10.1007/s10342-011-0542-0

Paquette A, Messier C (2010) The role of plantations in managing the world's forests in the Anthropocene. Front Ecol Environ 8:27-34. doi: $10.1890 / 080116$

Pausas JG, Austin MP (2001) Patterns of plant species richness in relation to different environments: an appraisal. J Veg Sci 12:153-166. doi: $10.2307 / 3236601$

Pielou E (1966) The measurement of diversity in different types of biological collections. J Theor Biol 13:131-144

Ramírez DA, Valladares F, Blasco A, Bellot J (2006) Assessing transpiration in the tussock grass Stipa tenacissima L.: the crucial role of the interplay between morphology and physiology. Acta Oecol 30:386-398. doi:10.1016/j.actao.2006.06.006

Rivas-Martínez S, Gandullo JM, Allué JL, González-Rebollar JL (1987) Memoria del mapa de series de vegetación de España: 1: 400.000. Serie Técnica ICONA. Ministerio de Agricultura, Pesca y Alimentación, Madrid 
Ruiz-Benito P, Gomez-Aparicio L, Zavala MA (2012) Large-scale assessment of regeneration and diversity in Mediterranean planted pine forests along ecological gradients. Divers Distrib 18:1092-1106. doi:10.1111/j.1472-4642.2012.00901.x

ter Braak CJF, Smilauer P (2012) Canoco 5. Software for multivariate data exploration, testing, and summarrization. Biometris, Plant Research International, Wageningen
Tutin TG, Heywood VH, Burges NA, Valentine DH, Walters SM, Moore DM (1986-1993) Flora Europaea, vol I-V. Cambridge University Press, London

Zavala MA, Zea E (2004) Mechanisms maintaining biodiversity in Mediterranean pine-oak forests: insights from a spatial simulation model. Plant Ecol 171:197-207 